\title{
EFFECTIVITY OF FLIPPED LEARNING COMBINED WITH TEAM BASED LEARNING TOWARDS ACADEMIC PERFORMANCE AND STUDENT STATISFACTION IN MEDICAL SURGICAL NURSING COURSE
}

\author{
Anselmus Aristo Parut ${ }^{*}$, Ni Luh Putu Inca Buntari Agustini \\ ${ }^{1,2}$ Sekolah Tinggi Ilmu Kesehatan Bali, Jl. Tukad Balian 180 Renon, Denpasar, Indonesia \\ Email*: arisparut2@gmail.com
}

\begin{abstract}
Introduction: Flipped classroom is an instructional model which is flipping the traditionally learning method used in class now being the homework for college students, while classes are conducted face to face using collaborative learning and inquiry-based learning method. This study aimed to explain the effectiveness of flipped classroom learning combined with team based learning toward learning achievement and satisfaction of nursing students. Methods: this was a quasi experimental study using non equivalent group post test only design. Population was year two students class $A$ and class $B$, sample size was 161 students which is 81 students from class $A$ and 80 students from class B. Results: more respondents were satisfied with flipped classroom learning combined with team based learning (92.6\%). Mean rank of group undertaking flipped classroom combined with team based learning were higher (96.90) compared to group undertaking traditional method (64.91). Mann-whitney showed that $p$ value $=0.000$ which means there was a different of learning achievement between group of student undertaking flipped classroom learning combined with team based learning and students undertaking traditional method. Conclusions : Flipped classroom combined with team based learning are more effective than the traditional learning. It is recommended to use mix-method and larger sample for further study.
\end{abstract}

Keywords : flipped learning, effectivity, learning achievement, nursing education

\section{INTRODUCTION}

Newly graduated nursing struggle to meet workplace requirements, there is a gap between nursing education and actual practice. The current nursing curriculum is overload with classroom time relying heavily on automated software presentations and ineffective teaching strategies that are not meeting the needs of today's nursing and healthcare facilities (Benner, 2009). There has been a call for a radical transformation in nursing education to address this gap, involving educators designing learning experiences that enhance education quality and ensure that graduates are prepared for today's complex nursing practice at different health care facilities (Benner, 2009; Yacout, 2016).

To meet learning needs of current undergraduate nursing students, and respond to mandates for bettered prepared graduates, nurse educators must restructure curricula and teaching strategies. One strategy to increased attention and active learning is the flipped classroom learning. Flipped teaching expected students to have completed preclass material, such as assigned reading, instructor-prepared lecture video(s), and PowerPoint slides. Inclass activities included the review of difficult topics, a modified team-based learning (TBL) session, and an individual assessment. Team based learning also appears to promote team participation and improved knowledge (Haidet, 2014). there is also evidence that flipped classroom learning combined with team based learning has increased student satisfaction and higher engagement compared to traditional lectures ( Sisk, 2011).

Various studies have been conducted to prove the effectiveness of flipped classroom learning method to improve students' learning motivation and satisfaction (Butzler, 2014). Flipped classroom can be applied to students who have high independence in learning and want some flexibility of time and place of learning. Related to nursing education institutions in Indonesia in its efforts to improve the learning achievement of student nurses, flipped classroom learning method has not been widely implemented.

In Flipped classroom method, involves a role change for lectures. Lectures or 
instructors minimizing the amount of direct instruction in their teaching practice while maximizing interaction between lecture and students, and more cooperative and collaborative contribution which can improve social interaction, teamwork among students. The role of students as active participant is very critical in flipped classroom method (Benner, 2009). Many studies reported that flipped classroom method had a positive effect on learning outcomes such as improving academic performance, critical thinking skill, teamwork, and self learning. However some studies also showed that there are no significant differences in final exam score between students who undertaking flipped classroom and traditional lectures (Tan,2017)

A meta analysis about effectiveness of flipped classrooms in nursing education by Tan (2017) showed that there are improvement in teaching satisfaction and study attitude among Chinese student but some western studies showed the contrary result. There are some reason why Chinese student prefer flipped classroom than traditional lectures. First usually in traditional Chinese nursing education, students are not allowed to use any kind of gadget such computer or smart phone, student are also remind quite and not allowed to discuss during lecture. Second, students have few opportunities to communicate with the lecturer after class.

The general objective of this research is to explain the effectiveness of flipped classroom learning combined with team based learning to improve learning achievement and satisfaction of nursing students. The specific objectives are: 1) apply the flipped classroom learning combined with team based learning, 2) identify students satisfaction and learning after the application of flipped classroom combined with team based learning, 3) identify, analysis and explain the effect of flipped classroom combined with team based learning on Bachelor of Nursing Program.

\section{METHODS}

This was a quasi experimental study with non equivalent group post test only design. Population was all nursing student, bachelor of nursing program STIKES Bali. Population was second year nursing students of STIKES Bali. Sample was class A and class
B students. Sample size was not calculated based on any formula because all members of population being study samples (total sampling).

This study was conducted on the second year nursing student, facilitator was the research team itself. The subject was Medical Surgical Nursing which facilitator was one of the medical surgical team. Study variables consist of: 1) the independent variable: the application of flipped classroom learning method combined with team based learning 2) dependent variables: learning achievement and student satisfaction, 3) control variables: teaching materials, frequency of face to face meetings in class, given assignments, facilitators; and 4) confounding variables: learning motivation, independence, study load, stress and environment. The instruments used for applying flipped classroom learning method were teaching plan, assignment description (individual and group), presence list and flash disk of study materials.

Learning achievement was assessed through individual and group assignments collected timely by assignment assessment rubrics. Individual assignment was done independently while group assignment was done collaboratively with group members @ 5-6 students. Assignment assessment rubrics of individual and group were made differently in order to facilitate a more detailed assessment; given group assignment has the aspects of team work / cooperation, leadership, tolerance and communication which were not found on the individual assignment. The data scale was ratio. Score range was 0 to 100 . The score of quiz, individual assignment summed with the group assignment then averaged and final exam, and then put into a statistical test (test of data normality and man whitney test). The study hypothesis was accepted if the significance of the data is less than $\alpha(0.05)$. Student satisfaction was assessed by a structured questionnaire. Questionnaire was design by researcher.

The research team proposed ethical review in Faculty of Medicine, Udayana University to obtain ethical clearance. The other ethical aspects applied were informed consent, anonymity and confidentiality.

\section{RESULTS}


Tabel 1. Demographic characteristic $(n=161)$

\begin{tabular}{lcc}
\hline \multicolumn{1}{c}{ Characteristic } & Frequency $(\mathbf{n = 1 6 1})$ & $\begin{array}{c}\text { Percentage (\%) } \\
(\mathbf{n = 1 6 1})\end{array}$ \\
\hline 1. Age & 1 & \\
a. 19 years old & 124 & 0.6 \\
b. 20 years old & 35 & 77 \\
c. 21 years old & 1 & 21.7 \\
d. 22 years old & & 0.6 \\
2. Gender & 31 & \\
a. Male & 130 & 19.3 \\
b. Female & & 80.7 \\
3. Religion & 157 & 97.5 \\
a. Hinduism & 2 & 1.2 \\
b. Islam & 1 & 0.6 \\
c. Catholic & 1 & 0.6 \\
d. Christian & & \\
\hline
\end{tabular}

Tabel 2. Student satisfaction towards flipped classroom learning combined with team based learning

\begin{tabular}{ccc}
\hline & Frequency $(\mathbf{n}=\mathbf{8 1})$ & Percentage $(\boldsymbol{\%})(\mathbf{n}=\mathbf{8 1})$ \\
\hline Not Satisfy & 0 & 0 \\
Less satisfy & 6 & 7.4 \\
Very satisfy & 75 & 92.6 \\
Total & 81 & 100 \\
\hline
\end{tabular}

Table 3. Learning achievement

\begin{tabular}{c|c|c|c|c|c|c}
\hline & \multicolumn{2}{c}{ Flipped } & \multicolumn{2}{c}{ Traditional } & \multicolumn{2}{c}{ Mean } \\
\cline { 2 - 8 } & n & \% & \multicolumn{1}{c}{ n } & \% & n & \% \\
\hline $0-33$ & 0 & 0 & 1 & 1,2 & 1 & 0,6 \\
\hline $34-67$ & 34 & 42 & 50 & 62.5 & 84 & 52.2 \\
$68-100$ & 47 & 58 & 29 & 36.2 & 76 & 47.2 \\
\hline \multicolumn{7}{c}{$\begin{array}{c}\text { Mann-Whitney test } \\
\text { Sig. (2-tailed) } \\
\text { p = 0,000 }\end{array}$} \\
\hline
\end{tabular}

Sample size was 161 which 81 class A students who undertaking flipped classroom combined with team based learning and 80 class B students who undertaking traditional learning. The demographic characteristic of study respondents are presented in table 1. Below.

Kolmogorov-Smirnov test result showed that the data learning achievement of student undertaking flipped classroom learning combined with team based learning and student undertaking traditional learning weren't normally distributed $(\mathrm{p}=0,035)$. Learning achievement of student undertaking flipped classroom learning combined with team based learning and traditional method are presented in table 3 below.

The value of learning achievement for student undertaking flipped classroom learning combined with team based learning were 47 students (58\%) got score between 68-100 and student who undertaking traditional method only 29 students $(36.2 \%)$ who got score 68 100. Statistic analysis showed that mean rank of group undertaking flipped classroom combined with team based learning were higher (96.90) compared to group undertaking traditional method (64.91). Man-whitney showed that $p$ value $=0.000<0.05$ which means there was a different of learning 
achievement between group of student undertaking flipped classroom learning combined with team based learning and students undertaking traditional method.

\section{DISCUSSIONS}

Flipped classroom learning is a promising student centered learning approach. Advance in technology provide easy-to-use tools for recording lecture and sharing these with students rather than traditional lecture. Although there is eagerness to implement this new strategy in nursing area, but there is limited evidence of its effectiveness on learning achievement. We conducted flipped classroom learning combined with team based learning compare with traditional learning on second year nursing students. Students performed better in flipped classroom learning combined with team based learning compared with traditional learning method. Other study reported similar positive result. Research of Gillispie (2016) conducted on medical students using case control design, in which the class using traditional method as the control group and the class using flipped classroom learning method as the intervention group. Results showed that the intervention group has increased score significantly compared with the control group.

Overall flipped classroom gives students the opportunity to be more critical in thinking, more independent in their learning process, and more active in interacting and discussing both with peers and the faculty. In this study, researchers also found that most students $(92,6 \%)$ are satisfied with flipped classroom learning combined with team based learning. Research of Papadopoulos \& Roman (2010) conducted on mechanical engineering students. Students are given a video of tutorial and learn it by themselves, then held discussions in class. Based on observations of researchers, students capture the knowledge more quickly and have a very good progress. But not all studies on flipped classroom gave a positive result. The success of flipped classroom application is also influenced by the student interest in the material provided (Strayer, 2012).

In this study there was a different of learning achievement between group of student undertaking flipped classroom learning combined with team based learning and students undertaking traditional method $(\mathrm{p}$ $=0.000)$. Other study reported that no significant difference from flipped learning compared with traditional learning when students work individually, but was able to demonstrate a positive result when students worked in cooperation with peer interaction (Foldnes, 2016). Our success in the flipped study, therefore, could be due to the incorporation of a team based learning session as part of in-class activity.

The positive feedback we received from students regarding flipped classroom learning combined with team based learning, 92.6\% students are satisfied with the learning method. Other study also reported the same result (Cotta, 2016; Gorres, 2016).

Although our study showed positive result favouring flipped learning combined with team based learning. The study design had limitations, only one lecture who applied flipped classroom learning, other part of the team still applied traditional learning. Two groups (flipped and traditional) were in the same campus which increase the chance of students share the material given prior to class and increase bias.

\section{CONCLUSIONS}

Our findings suggest that flipped learning is more effective than the traditional learning. This could be due to the incorporation of a team based learning session as part of in-class activity. Whether flipped classroom learning is effective for medical surgical nursing, certain subjects is yet to be tested. Other researchers can conduct further research using mixed-method paradigm and a larger sample size together with experienced / trained flipped classroom instructors so that the effectiveness in many aspects of nursing education could be identified and evaluated.

\section{ACKNOWLEDGMENTS}

We sincerely thanks to Association of Indonesian Nurse Education Center (AINEC) for funding this study.

\section{REFERENCES}


Benner, P., Sutphen, M., Leonard, V. \& Day, L. (2009). Educating nurses: A call for radical transformation. San Francisco, CA: Jossey-Bass.

Bergmann, J., \& Sams, A. (2012). Flip your classroom: Reach every student in every class every day. Eugene, OR: International Society for Technology in Education.

Bristol, T. (2014). "Flipping the Classroom." Teaching and Learning in Nursing 9.1 (2014): 43-46. Print.

Butzler, K.B. (2014). The Effects of Motivation on Achievement and Satisfaction in a Flipped Classroom Learning Environment. Diunduh dari: www.proquest.com

Center For Digital Education. (2012). The Flipped Classroom: Increasing Instructional Effectiveness in Higher Education with Blended Learning Technology.

http://echo360.com/sites/default/files/Fli pped\%20Classroom\%20Brief.pdf

Cotta KI, Shah S, Almgren MM, MarcíasMoriarity LZ, Mody V.(2016). Effectiveness of flipped classroom instructional model in teaching pharmaceutical calculations. Curr Pharm Teach Learn 8: 646-653

Felder, R.M. (2012). Engineering education-A tale of two paradigms. In SFGE, 2nd. International Conference on Geotechnical Engineering Education, Galway.

Foldnes N (2016). The flipped classroom and cooperative learning: Evidence from a randomized experiment. Active Learn High Educ 17: 39-49.

Gillisipie, V. (2016). Using the Flipped Classroom to Bridge the Gap to
Generation Y. Ochsner Journal. 16:3236

Gorres-Martens BK, Segovia AR, Pfefer MT.(2016). Positive outcomes increase over time with the implementation of a semiflipped teaching model. $A d v$ Physiol Educ 40: 32-37.

Haidet, P., Kubitz, K., McCormack, W.T., (2014). Analysis of the team-based learning literature:TBL comes of age. J. Excell.

Coll. Teach. 3-4 (25), 303-

Papadapoulos, C. \& Roman, A. S. (2010). Implementing an inverted classroom model in engineering statistics: Initial results. American Society for Engineering Statistics. Proceedings of the 40th ASEE/IEEE Frontiers in Education Conference, Washington, DC, October 2010

Sisk, R.J., (2011). Team-based learning: systematic research review. J. Nurs. Educ. 50 (12),665-669.

Strayer, J. (2012). How learning in an inverted classroom influences cooperation, innovation and task Orientation. Learning Environments, 15(2), 171.

Tan C, Yue WG, Fu Y. (2007).Effectiveness of flipped classroom in nursing education : systematic review and metaanalysis. Chinese Nursing Research. 4:192-200

Transformation. San Francisco, CA: Jossey-Bass.

Valiga, T. "Nursing Education Trends: Future Implications and Predictions." Nursing Clinics of North America 47 (2012): 423-34

Yacout DAESA, Shosha AAEFA. (2016).

Nursing students' perceptions towards flipped classroom educational strategy. J Am Sci.;12:62-75. 